\title{
Retraction Note to: Alpinumisoflavone rescues glucocorticoid-induced apoptosis of osteocytes via suppressing Nox2-dependent ROS generation
}

\author{
Editorial Office of Pharmacological Reports ${ }^{1}$
}

Published online: 18 January 2021

(c) Maj Institute of Pharmacology Polish Academy of Sciences 2021

\section{Retraction Note to: \\ Pharmacological Reports 70 (2018) 270-276 \\ https://doi.org/10.1016/j.pharep.2017.11.001}

The Editor in Chief has retracted this article [1] because of concerns regarding similarities between Fig. 1C and Fig. 3D, which question the integrity of the data. The authors did not respond to request for an explanation or additional data. The Editor-in-Chief therefore no longer has confidence in the integrity of the data in this article.
None of the authors has responded to any correspondence from the editor or publisher about this retraction.

\section{Reference}

1. Yin J, Han L, Cong W. Alpinumisoflavone rescues glucocorticoidinduced apoptosis of osteocytes via suppressing Nox2-dependent ROS generation. Pharmacol Rep. 2018;70:270-6. https://doi. org/10.1016/j.pharep.2017.11.001.

1 Kraków, Poland 